\title{
Ground motion prediction equation for earthquakes along the Western Himalayan arc
}

\author{
Srinagesh $^{1, *}$, S. K. Singh ${ }^{2}$, D. Arroyo ${ }^{3}$, D. Srinivas ${ }^{1}$, G. Suresh ${ }^{4}$ and G. Suresh ${ }^{1}$ \\ ${ }^{1}$ CSIR-National Geophysical Research Institute, Uppal Road, Hyderabad 500 007, India \\ ${ }^{2}$ Universidad Nacional Autónoma de México. Instituto de Geofísica, Circuito de la Investigación s/n, Ciudad Universitaria, Coyoacán, \\ Mexico City 04510, Mexico \\ ${ }^{3}$ Departamento de Materiales, Universidad Autónoma Metropolitana, Avenida San Pablo 180, Reynosa Tamaulipas, Azcapotzalco, \\ Mexico City 02200 , Mexico \\ ${ }^{4}$ National Centre for Seismology, India, Mausam Bhavan Complex, Lodi Road, New Delhi 110 003, India
}

A critical element in seismic hazard estimation is the ground motion prediction equation (GMPE) which relates expected seismic intensity at a point from an earthquake of a given magnitude and location. Presently available GMPEs for plate interface thrust earthquakes along the Himalayan arc suffer from limited number of strong motion recordings used in their derivation. In this study we use a larger dataset, including recordings from the 2015 Gorhka, Nepal earthquake $\left(M_{w}\right.$ 7.9) and some of its larger aftershocks, to derive GMPE for earthquakes along the Western Himalayan arc. The proposed GMPE should give more reliable estimation of ground motion parameters at hard sites along the arc and in Peninsular India, and at soft sites in the Indo-Gangetic Plains.

Keywords: Active tectonics, ground motion prediction equation, plate interface earthquake, seismic hazard.

SEISMICITY along the Himalayan arc is a consequence of continent-to-continent collision of the Indian and Eurasian Plates. The Himalaya accommodates about half of the $40 \mathrm{~mm} /$ year convergence rate between the two plates $^{1-4}$. The arc has been the site of four $M \sim 8$ earthquakes in the last 120 years: 1905 Kangra, 1934 BiharNepal border, 1950 Arunachal Pradesh and 2015 Gorkha. Assuming that the measured surface strain is elastic, Stevens and Avouac ${ }^{4}$ estimated the seismic moment build-up rate of $15.1 \pm 1.1 \times 10^{19} \mathrm{Nm}$ /year along the arc which extends from $73^{\circ} \mathrm{E}$ to $96^{\circ} \mathrm{E}$, roughly $2000 \mathrm{~km}$ in length. As a consequence, towns and cities along the arc and the densely-populated Indo-Gangetic Plains (IGP) are exposed to extremely high seismic hazard ${ }^{5}$.

A critical element in the estimation of seismic hazard is the ground motion prediction equation (GMPE) which relates ground motion at a point from an earthquake of a given magnitude and location. There are several studies dealing with this issue for plate interface thrust earthquakes along the Himalayan arc. They can be broadly divided in two groups: the first is based on regression

\footnotetext{
*For correspondence. (e-mail: srinagesh@ngri.res.in)
}

analysis of recorded data ${ }^{6-10}$, and the second takes recourse to the stochastic method ${ }^{1-14}$.

The regression studies suffer from limited data available from the earthquakes along the arc. To compensate for this limitation, one study merged data from shallow, plate interface thrust earthquakes along the Western Himalayan arc with those from deeper events from North East India with dominant strike-slip focal mechanisms as well as with recordings from the Zagros region of $\operatorname{Iran}^{7}$. Facing the same difficulty, another study combined the scarce data with theoretically derived attenuation laws ${ }^{15}$. In the face of meagre available data, GMPEs based on stochastic method ${ }^{16}$ have been explored in references 11-14.

To meet the urgent need of a more extensive dataset from the Himalayan earthquakes, a strong-motion velocity seismograph network in the central part of IGP named as CIGN was installed in 2012 (ref. 17). In 2005, the Indian Institute of Technology, Roorkee (IIT-R) began deployment of digital accelerographs in northern India ${ }^{18}$. These two networks recorded the 2015 Gorkha, Nepal earthquake $\left(M_{\mathrm{w}} 7.9\right)$ and some of its aftershocks. The recordings produced by these two networks are described and analysed by Singh et al. ${ }^{9}$. Based mostly on the recordings of the Gorkha earthquake sequence by these networks, Singh et al. ${ }^{9}$ proposed a GMPE for the IGP.

The 2015 Gorkha, Nepal earthquake sequence was also recorded at hard sites along the arc and in Peninsular India. In this study, we use all recordings generated by this sequence and from other earthquakes in the western part of the Himalayan arc up to a distance of $600 \mathrm{~km}$ (Figure 1) to derive a GMPE for hard as well as soft sites. Since this GMPE uses a larger dataset than the previous ones, it should provide more reliable estimate of ground motion parameters from the postulated earthquakes.

In the derivation of the GMPE, we exclude recordings of plate interface earthquakes of the Eastern Himalayan arc for two reasons. First, the active tectonics of Eastern and Western Himalaya differs. The zone of deformation in the Eastern Himalaya is wider and the tectonics is more complex. In this region, the Indian Plate underthrusts beneath the Eastern Himalaya towards the north. 


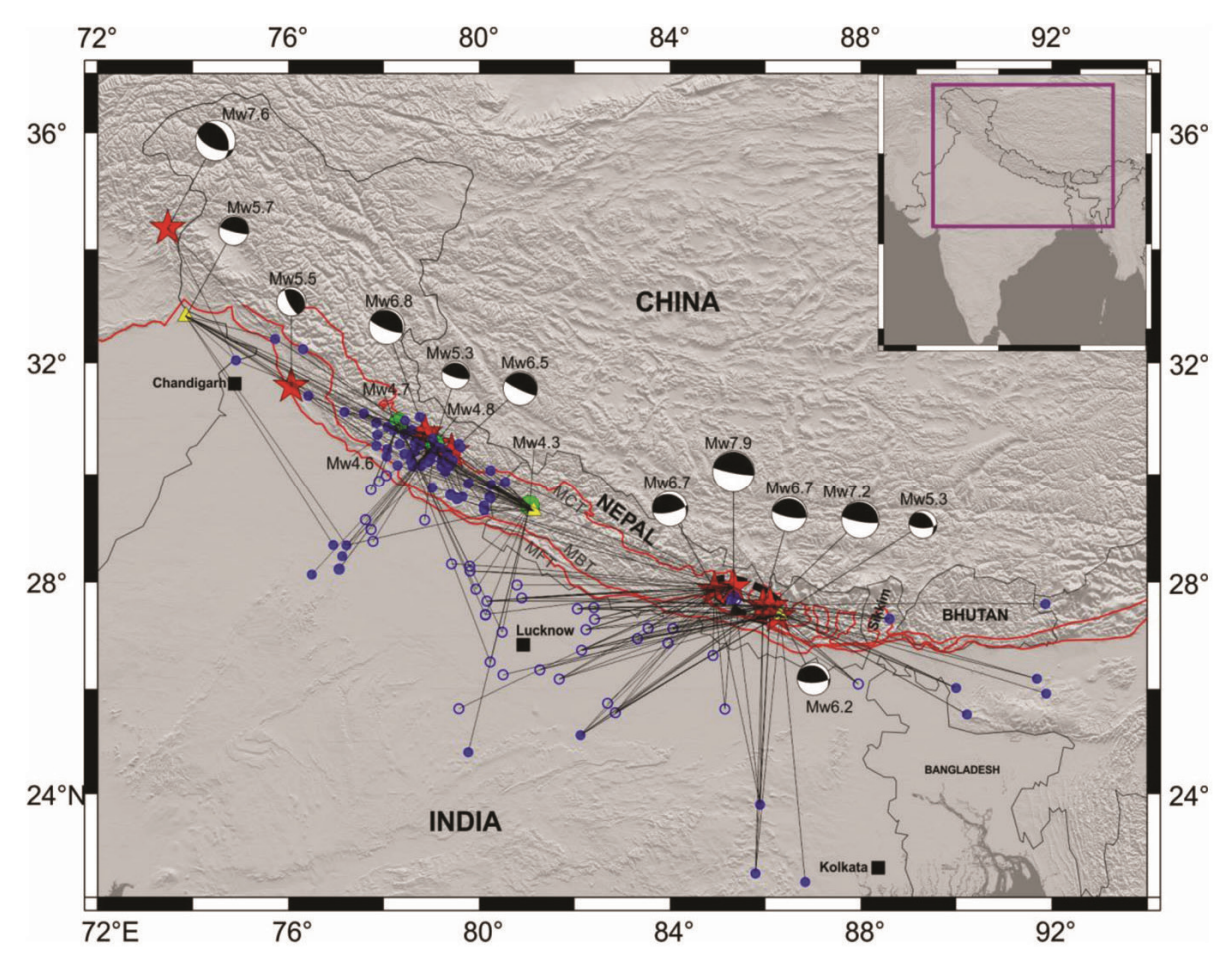

Figure 1. Location map of the Western Himalayan arc. Epicentres of the earthquakes whose recordings were used in the derivation of ground motion prediction equation (GMPE) are shown by red star if the focal mechanism is known and by green dot if it is not known. Yellow triangles give the location of events whose recordings were used to test the performance of the GMPE (see text). Elliptical dashed contour delineates rupture area of the 2015 Nepal main shock $\left(M_{\mathrm{w}} 7.9\right)$. Blue filled in circles and open circles are hard and soft sites respectively, where the earthquakes were recorded. Paths from events to recording sites are shown by straight lines. Few important cities in India are marked by rectangles. MFT, MBT and MCT denote Main Frontal Thrust, Main Boundary Thrust and Main Central Thrust respectively.

There is an east-west convergence and oblique subduction of the Indian Plate below the Burmese Microplate. There is also over-thrusting of the uplifted Shillong Plateau northward over the Brahmaputra Valley and strike-slip motion in the Kopili Fault Zone. The complexity of the tectonics is reflected in the diversity of the focal mechanisms, and spatial and depth distribution of the earthquakes ${ }^{19}$. Tomography of attenuation parameter, $Q$, also reveals a complex pattern in the region ${ }^{20}$. For these reasons, it is likely that the GMPEs of earthquakes in the Eastern and Western Himalaya are different. Second, moderate and large, shallow-dipping, plate interface thrust earthquakes $\left(M_{\mathrm{w}} \geq 5\right)$ are infrequent in eastern Himalaya. CSIR-National Geophysical Research Institute (NGRI), Hyderabad and National Centre for Seismology (NCS, Delhi) began operation of seismic/accelerographic networks in NE India in 2007 and 2011 respectively. Since 2007, the Global Centroid Moment Tensor (GCMT) catalogue lists four $M_{\mathrm{w}} \geq 5$ plate interface earthquakes in the area defined by $26.5^{\circ}-29.5^{\circ} \mathrm{N}$ and $87^{\circ}$ $96^{\circ} \mathrm{E}$, which includes Eastern Himalaya. In view of the small number of earthquakes, it is not possible to construct a GMPE for the Eastern Himalayan arc separately. Because of the difference in active tectonics, we also consider it inadvisable to merge the recordings from these events with those from Western Himalaya.

\section{Data}

Our goal was to select all moderate and large $\left(M_{\mathrm{w}} \geq 5\right)$, shallow-dipping, plate interface thrust earthquakes along the western Himalayan arc that gave rise to multiple recordings within epicentral distance $(R) \leq 600 \mathrm{~km}$. Due to scarcity of data, we had to relax these requirements. Thus, we included the 2005 Pakistan $\left(M_{\mathrm{w}} 7.6\right)$ earthquake, even though it produced only two recordings (Figure 1). We also included four events between $4.3 \leq M_{\mathrm{w}} \leq 4.9$ with unknown focal mechanisms. There may be other wellrecorded $M_{\mathrm{w}} \leq 4.9$ events along the Western Himalayan arc, whose recordings were not accessible to us. However, it is unlikely that we have missed any $M_{\mathrm{w}} \geq 5$ event with multiple recordings. Our analysis is based on the recordings of 14 shallow Himalayan arc earthquakes $(4.3 \leq$ $M_{\mathrm{w}} \leq 7.9$; Table 1). The dataset includes four events from the 2015 Gorkha, Nepal earthquake sequence. Recordings of the following three western Himalayan arc earthquakes were not used in the regression analysis: an aftershock of 

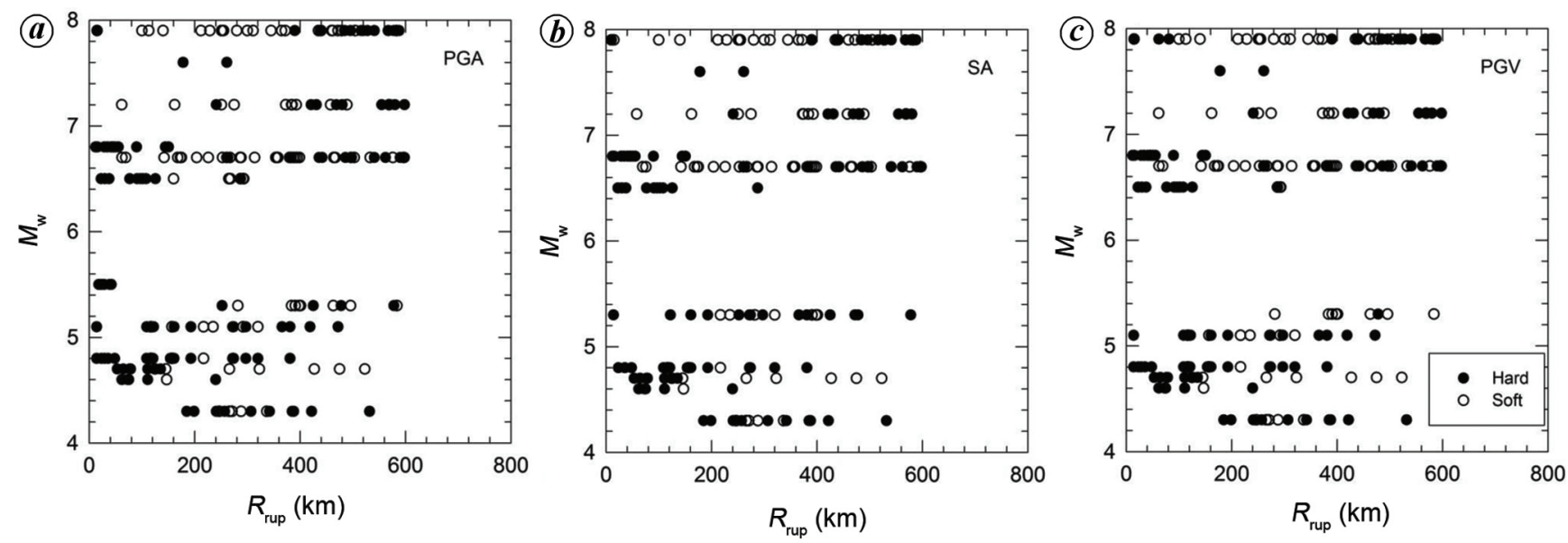

Figure 2. Magnitude $\left(M_{\mathrm{w}}\right)$ versus distance $\left(R_{\mathrm{rup}}\right)$ plot summarizing the data used in the derivation of GMPE for (a) Peak Ground Acceleration (PGA), (b) spectral acceleration and (c) Peak Ground Velocity (PGV).

Table 1. Western Himalayan arc earthquakes used in the derivation of ground-motion prediction equation (GMPE)

\begin{tabular}{|c|c|c|c|c|c|c|c|c|c|}
\hline $\begin{array}{l}\text { Event } \\
\text { number }\end{array}$ & Region & Date $\mathrm{Y} / \mathrm{M} / \mathrm{D}$ & $\begin{array}{l}\text { Latitude } \\
\left({ }^{\circ} \mathrm{N}\right)\end{array}$ & $\begin{array}{l}\text { Longitude } \\
\qquad\left({ }^{\circ} \mathrm{E}\right)\end{array}$ & $\begin{array}{c}\text { Depth } \\
(\mathrm{km})\end{array}$ & $M_{w}$ & $\varphi$ & $\delta$ & $\lambda$ \\
\hline 2 & Uttarkashi, Uttarakhand & 1991/10/19 & $30.75^{\mathrm{a}}$ & 78.86 & $12^{\mathrm{b}}$ & $6.8^{\mathrm{b}}$ & $317^{\mathrm{b}}$ & 14 & 115 \\
\hline 3 & Chamoli, Uttarakhand & $1999 / 03 / 28$ & $30.41^{\mathrm{a}}$ & 79.42 & $21^{\mathrm{a}}$ & $6.5^{\mathrm{b}}$ & $280^{\mathrm{b}}$ & 7 & 75 \\
\hline 6 & Nepal & $2008 / 06 / 15$ & $29.42^{\mathrm{d}}$ & 81.06 & $26^{\mathrm{d}}$ & $4.3^{\mathrm{c}}$ & & NA & \\
\hline 7 & Uttarkashi, Uttarakhand & $2012 / 02 / 09$ & $30.94^{\mathrm{a}}$ & 78.31 & $10^{\mathrm{a}}$ & $4.6^{\mathrm{e}}$ & & NA & \\
\hline 8 & Nepal (main shock) & $2015 / 04 / 25$ & $27.91^{\mathrm{b}}$ & 85.33 & $12^{\mathrm{b}}$ & $7.9^{\mathrm{b}}$ & $287^{\mathrm{b}}$ & 6 & 96 \\
\hline 9 & Nepal (aftershock A1) & $2015 / 04 / 25$ & $27.86^{\mathrm{b}}$ & 84.93 & $21^{\mathrm{b}}$ & $6.7^{\mathrm{b}}$ & $301^{\mathrm{b}}$ & 23 & 131 \\
\hline 10 & Nepal (aftershock A2) & $2015 / 04 / 26$ & $27.56^{\mathrm{b}}$ & 85.95 & $21^{\mathrm{b}}$ & $6.7^{\mathrm{b}}$ & $289^{\mathrm{b}}$ & 14 & 98 \\
\hline
\end{tabular}

${ }^{\mathrm{a}}$ India Meteorological Department/National Centre of Seismology catalogue. ${ }^{\mathrm{b}}$ Global CMT catalogue. ${ }^{\mathrm{c}}$ Singh et al. ${ }^{13}$. International Seismological Centre catalogue. ${ }^{\mathrm{e}}$ Srinagesh et al. ${ }^{14}$. ${ }^{\mathrm{f}} \mathrm{Nepal}$ aftershock $4\left(2015 / 05 / 12 ; 07: 36 ; M_{\mathrm{w}} 6.2\right)$ is listed in Table 2. Data from aftershock 4 were not used in the regression analysis because the seismograms were contaminated from the coda of aftershock 3 .

the Gorkha, Nepal earthquake of 12 May $2015\left(M_{\mathrm{w}} 6.2\right)$, Pakistan earthquake of 24 September $2019\left(M_{\mathrm{w}}\right.$ 5.7), and Nepal earthquake of 19 November 2019 ( $\left.M_{\mathrm{w}} 4.7\right)$. Table 2 provides the source parameters of these events. The recordings of the 2015 aftershock were omitted because they were contaminated from the coda of an earlier event (aftershock 3, Table 1). Pakistan and Nepal earthquakes, on the other hand, occurred after the derivation of the GMPE. However, data from these earthquakes are used to test the performance of the derived GMPE.

The focal mechanisms are available for the larger events $\left(M_{\mathrm{w}} \geq 5.2\right)$. They are consistent with rupture on shallow-dipping thrust faults. We assume that the smaller events also had similar focal mechanisms. The assumption seems reasonable in view of the locations and depths of the events (Tables 1 and 2 and Figure 1).

Thickness of the sediments in the IGP increases from south to north, reaching a depth of $\sim 4 \mathrm{~km}$ near the foothills of the Himalaya. The sedimentary column has been modelled by two layers overlying a basement ${ }^{21,22}$. Shear-wave velocity in the soft alluvial upper layer is between 0.2 and $1.3 \mathrm{~km} / \mathrm{s}$. The US National Earthquake Hazard Reduction Programme (NEHRP) assigns sites in different classes based on the average shear-wave speed in the upper $30 \mathrm{~m}(\mathrm{Vs} 30)$. Site classes C, D, and E correspond to Vs30 between 360 and 760,180 and $360 \mathrm{~m} / \mathrm{s}$, and less than $180 \mathrm{~m} / \mathrm{s}$ respectively. Vs30 values available at Kanpur and Lucknow correspond to class D of NEHRP. The IGP sites have a variable shear speed in the upper $30 \mathrm{~m}$ and most likely belong to class C, D or E. In this study, we classified all stations in the IGA as soft sites, while those in the arc and in Peninsular India were grouped as hard sites.

Figure 2 shows magnitude $\left(M_{\mathrm{w}}\right)$ versus distance $\left(R_{\text {rup }}\right)$ plot summarizing the data used in deriving the GMPE. Here $R_{\text {rup }}$ defines the closest distance to the rupture 
surface. For the Gorkha main shock, this surface is outlined by an elliptical area in Figure 1. A circular area of $25 \mathrm{~km}$ radius, centred at the hypocentre, is taken as the rupture surface of the $M_{\mathrm{w}} 7.2$ aftershock 3. For smaller earthquakes, listed in Table 1, the rupture area $A$ is assumed to be circular and estimated from the relation $M_{\mathrm{w}}=\log A+$ 4.0 ( $A$ in sq. $\mathrm{km}$ ). For the Nepal sequence, data from CIGN and IIT-R networks in the IGP were augmented with accelerograms at the soft sedimentary sites of KATNP, TVU, PTN and THM located in the Kathmandu Valley. KATNP recorded all Nepal events considered in this study. Accelerograms at TVU, PTN and THM were available only for the main shock $^{23}$. For the main shock, peak ground velocities (PGVs) at KKN4 and NAST, two continuous GPS stations (5 samples/s) located at nearfield hard and soft sites in Kathmandu region, were also included in the analysis.

Here we will consider the ground motion parameters of peak ground acceleration (PGA), PGV and 5\% damped pseudo spectral acceleration $\left(S_{\mathrm{a}}\right)$ at a given period. These parameters are also called the seismic intensities. The number of recordings in our dataset depends on the seismic intensity under consideration, which is based on the availability and quality of the records. For example, continuous GPS recordings at KKN4 and NAST could only be used to obtain PGVs. The accelerograms of the 1986 Kangra $\left(M_{\mathrm{w}} 5.5\right)$ and 1991 Uttarkashi $\left(M_{\mathrm{w}} 6.8\right)$ earthquakes are of relatively poor quality and short duration. Although these records are not suitable for spectral analysis, the PGA values of the 1986 earthquake, and the PGA and PGV values of the 1991 earthquake are reliable. For these reasons, we carefully examined each of the recordings to determine the seismic intensities that could be reliably estimated from it and used them in the development of the GMPE.

For PGA, there are 228 recordings (114 from the 2015 Gorkha, Nepal earthquake sequence and 114 from other earthquakes). For the response spectra, $S_{\mathrm{a}}$, we could use 197 recordings (107 from the 2015 Gorkha, Nepal sequence and 90 from other earthquakes). Finally, for PGV we have 219 recordings (117 from the 2015 Gorkha, Nepal sequence and 102 from other earthquakes).

The PGA dataset includes 124 records at soft and 104 at hard sites, while $S_{a}$ dataset consists of 91 at soft and 106 at hard sites. The PGV dataset is composed of 118 at soft and 101 at hard sites. We note that our dataset is larger than the one used in the derivation of the previous GMPE for the IGP sites ${ }^{9}$. For comparison, the dataset used in the derivation of GMPE by Sharma et al. ${ }^{7}$ comprised 201 records (58 from India and 143 from Iran), of which 69 were at hard sites and 132 at soft sites. These recordings were produced by 16 earthquakes: 6 from India (three each with reverse faulting and strike-slip faulting) and 10 from Iran (5 each with reverse and strike-slip faulting). Of the six Himalayan arc earthquakes, three were from western part of the arc. The recordings of only these three events are common between the study of Sharma et $a l^{7}$ and the present study (events 1, 2 and 3 in Table 1).

\section{Regression analysis}

To derive the GMPE we considered a functional form that is based on an approximate solution of a circular finite-source model $\mathrm{l}^{24,25}$

$$
\begin{aligned}
& \ln y=\alpha_{1}+\alpha_{2} M_{\mathrm{w}}+\alpha_{3} \\
& \times \ln \left[\frac{E_{1}\left(\alpha_{4} R_{\text {rup }}\right)-E_{1}\left(\alpha_{4} \sqrt{R_{\text {rup }}^{2}+r_{0}^{2}}\right)}{r_{0}^{2}}\right]+\alpha_{5} S, \\
& r_{0}^{2}=1.4447 \times 10^{-5} \mathrm{e}^{2.3026 M},
\end{aligned}
$$

where $y$ is the geometric mean of the two horizontal components of a seismic intensity (PGA in $\mathrm{cm} / \mathrm{s}^{2}$, or PGV in $\mathrm{cm} / \mathrm{s}$, or $S_{a}$ at a given period in $\left.\mathrm{cm} / \mathrm{s}^{2}\right), r_{0}$ the radius of a circular fault corresponding to a $M_{\mathrm{w}}$ and a stress drop of $10 \mathrm{MPa}, S$ a dummy variable that we use to model the two soil categories (it is equal to 1 for soft sites and 0 otherwise) and $E_{1}(x)$ is the well-known exponentialintegral function which is defined as

$$
E_{1}(x)=\int_{x}^{\infty} \frac{\mathrm{e}^{-t}}{t} \mathrm{~d} t .
$$

The coefficients $\alpha_{1}, \alpha_{2}, \alpha_{3}, \alpha_{4}$ and $\alpha_{5}$ are determined using regression analysis.

A desirable feature of this functional form is that the third term simultaneously accounts for near-source saturation effect, geometric spreading, anelastic attenuation and dependence of attenuation on magnitude ${ }^{24}$. As $R_{\text {rup }}$ approaches infinity, this term tends to $e^{-\alpha_{4} R_{\text {rup }}} / 2 R_{\text {rup }^{2}}$. Thus, the geometrical spreading and anelastic attenuation of seismic intensity $y$ is given by $\left[-\left\{\alpha_{3} \alpha_{4} R_{\text {rup }}+\right.\right.$ $\left.2 \alpha_{3} \ln \left(R_{\text {rup }}\right)\right\}$ ]. When $R_{\text {rup }}$ becomes comparable to $r_{0}$, then the near-source effect is controlled by coefficient $\alpha_{4}$. As $\alpha_{4}$ increases, the saturation of $y$ increases; on the other hand, as $\alpha_{4}$ becomes zero, the saturation vanishes. The attenuation is magnitude-dependent because the third term in eq. (1) depends on $r_{0}$.

We performed regression analysis through a Bayesian scheme developed earlier ${ }^{26-28}$. In the Bayesian scheme, the regression coefficients and standard deviation of the residuals are considered random variables whose prior probability density is known and the prior densities are updated with observations using Bayes' theorem. A detailed discussion of the Bayesian framework can be found elsewhere ${ }^{27,28}$. The prior information required by the Bayesian scheme was set following a previous 
Table 2. Western Himalayan arc earthquakes used to test the performance of GMPE derived in this study

\begin{tabular}{lcccccccc}
\hline & & & & \multicolumn{3}{c}{ Focal mechanism } \\
\cline { 6 - 9 } Region & Date Y/M/D & Latitude $\left({ }^{\circ} \mathrm{N}\right)$ & Longitude $\left({ }^{\circ} \mathrm{E}\right)$ & Depth $(\mathrm{km})$ & $M_{\mathrm{w}}$ & $\varphi$ & $\delta$ & $\lambda$ \\
\hline Nepal (aftershock A4) & $2015 / 05 / 12$ & $27.39^{\mathrm{a}}$ & 86.31 & $18^{\mathrm{a}}$ & $6.2^{\mathrm{a}}$ & $303^{\mathrm{a}}$ & 23 & 123 \\
Pakistan & $2019 / 09 / 24$ & $32.83^{\mathrm{a}}$ & 73.85 & $15^{\mathrm{a}}$ & $5.7^{\mathrm{a}}$ & $246^{\mathrm{a}}$ & 10 & 52 \\
Nepal & $2019 / 11 / 19$ & $29.32^{\mathrm{b}}$ & 81.14 & $10^{\mathrm{b}}$ & $4.7^{\mathrm{c}}$ & NA \\
\hline
\end{tabular}

${ }^{\mathrm{a}}$ Global CMT catalogue. ${ }^{\mathrm{b}} \mathrm{US}$ Geological Survey/National Earthquake Information Service. ${ }^{\mathrm{c}}$ From spectral analysis of $S$-waves recorded at local/regional distances (this study).

Table 3. Coefficients of GMPE for the Western Himalayan arc earthquakes

\begin{tabular}{lcccccccc}
\hline$T(\mathrm{sec})$ & $\alpha_{1}$ & $\alpha_{2}$ & $\alpha_{3}$ & $\alpha_{4}$ & $\alpha_{5}$ & $\sigma$ & $\sigma_{\mathrm{e}}$ & $\sigma_{\mathrm{r}}$ \\
\hline 0.1 & -0.406 & 1.150 & 0.286 & 0.015 & 0.104 & 0.721 & 0.490 & 0.529 \\
0.25 & -1.069 & 1.244 & 0.281 & 0.015 & 0.689 & 0.787 & 0.538 & 0.574 \\
0.35 & -1.622 & 1.307 & 0.276 & 0.015 & 0.723 & 0.765 & 0.444 & 0.623 \\
0.5 & -1.688 & 1.401 & 0.371 & 0.008 & 0.720 & 0.772 & 0.523 & 0.568 \\
0.6 & -1.806 & 1.454 & 0.414 & 0.007 & 0.720 & 0.761 & 0.489 & 0.583 \\
0.75 & -3.874 & 1.557 & 0.276 & 0.015 & 0.733 & 0.805 & 0.478 & 0.648 \\
1 & -3.972 & 1.639 & 0.387 & 0.007 & 0.885 & 0.832 & 0.597 & 0.580 \\
1.25 & -5.696 & 1.699 & 0.261 & 0.015 & 0.905 & 0.826 & 0.654 & 0.504 \\
1.5 & -6.070 & 1.792 & 0.312 & 0.011 & 0.947 & 0.814 & 0.561 & 0.590 \\
1.75 & -7.219 & 1.866 & 0.260 & 0.015 & 0.951 & 0.868 & 0.679 & 0.541 \\
2 & -6.746 & 1.896 & 0.360 & 0.008 & 0.969 & 0.863 & 0.746 & 0.433 \\
2.5 & -6.857 & 1.863 & 0.372 & 0.007 & 1.081 & 0.843 & 0.699 & 0.472 \\
3 & -8.058 & 1.992 & 0.366 & 0.007 & 1.174 & 0.856 & 0.720 & 0.462 \\
4 & -8.375 & 2.069 & 0.422 & 0.006 & 1.186 & 0.881 & 0.742 & 0.475 \\
5 & -9.040 & 2.195 & 0.478 & 0.004 & 1.163 & 0.834 & 0.700 & 0.454 \\
6 & -9.498 & 2.243 & 0.505 & 0.003 & 1.126 & 0.858 & 0.730 & 0.451 \\
PGA & -0.862 & 1.197 & 0.314 & 0.015 & 0.480 & 0.692 & 0.507 & 0.471 \\
PGV & -3.982 & 1.564 & 0.535 & 0.004 & 0.760 & 0.648 & 0.468 & 0.448 \\
\hline
\end{tabular}

study $^{24}$. We set the prior mean value of the coefficient $\alpha_{2}$ to unity and assigned a value of 0.7 to the prior standard deviation of $\alpha_{2}$. The prior mean value of the coefficient $\alpha_{3}$ was set at 0.5 and a value of 0.35 was assigned to the prior standard deviation of $\alpha_{3}$. This means that a priori we consider that geometric spreading is close to $1 / R$. Since $\alpha_{1}$ and $\alpha_{5}$ depend on the site effect, we leave these coefficients free by assigning a high standard deviation to their mean prior values. For simplicity, the coefficient $\alpha_{4}$ was not modelled explicitly as a random variate. We performed the regression analysis with different values of $\alpha_{4}$ to find the value that was related to the minimum bias. The method also requires the prior mean value of the standard deviation of the residuals $\left(\sigma_{\mathrm{p}}\right)$. We set $\sigma_{\mathrm{p}}=0.7$, a common value in the literature for GMPEs, and assigned a value of 0.35 to the prior mean value of $\sigma_{\mathrm{e}}$.

In the construction of a GMPE, it is accepted that the residuals during the same earthquake are correlated while those during different earthquakes are uncorrelated. The total residual is composed of intra-event residuals (residuals for different sites during the same earthquake) and inter-event residuals (event-to-event residuals). The results are given in Table 3 , where $\sigma, \sigma_{\mathrm{e}}$ and $\sigma_{\mathrm{r}}$ are the aleatory variability, inter-event variability and intra-event variability (i.e. standard deviation of the total residual, inter-event residual and intra-event residual) respectively.
Since we are dealing with a nonlinear regression analysis, it is important to assess the bias of the model. For this, we include plots of residuals for different intensities as a function of $M_{\mathrm{w}}$ and $R_{\text {rup }}$ in Figures 3 and 4 respectively. The residuals are unbiased with respect to $R_{\text {rup }}$ because they are fairly independent of the same $R_{\text {rup }}$. However, a moderate bias is seen with respect to $M_{\mathrm{w}}$ since the residuals tend to increase for $4<M_{\mathrm{w}}<5$ and decrease for $M_{\mathrm{w}}<6.5$. We computed the mean residual for four one-unit $M_{\mathrm{w}}$ bins centred at $M_{\mathrm{w}} 4.5,5.5,6.5$ and 7.5 for PGA and PGV. For PGA the mean residual for each bin is $-0.206,0.214,0.157$ and -0.458 respectively while for PGV the mean residual for each bin is -0.206 , $0.106,0.109,-0.304$ respectively. The larger bias is observed for $M_{\mathrm{w}}$ between 7 and 8, where the GMPE systematically predicts larger intensities than the observed ones.

The bias with respect of $M_{\mathrm{w}}$ is most likely due to deficient radiation at intermediate and high frequencies during the main shock of the Gorkha sequence. This is evidenced from the spectral ratios of the main shock to several of its aftershocks ${ }^{9}$. Since spectral ratio eliminates the path and site effects, the deficiency is attributable to the source.

After several tests and in view of the scarcity of data, we decided to keep the model simple, abstaining from correcting the bias by including additional terms to the 

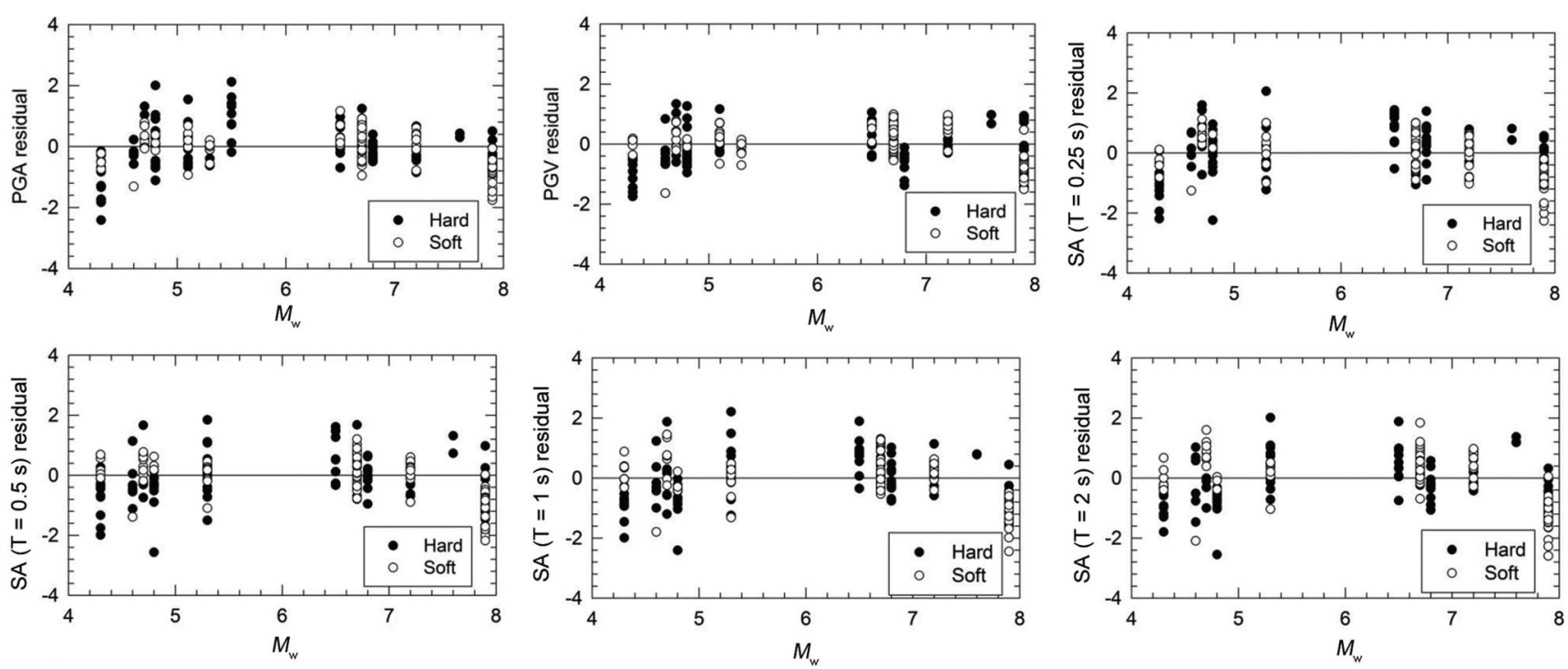

Figure 3. Residuals in natural logarithmic unit as a function of magnitude for the proposed GMPE.
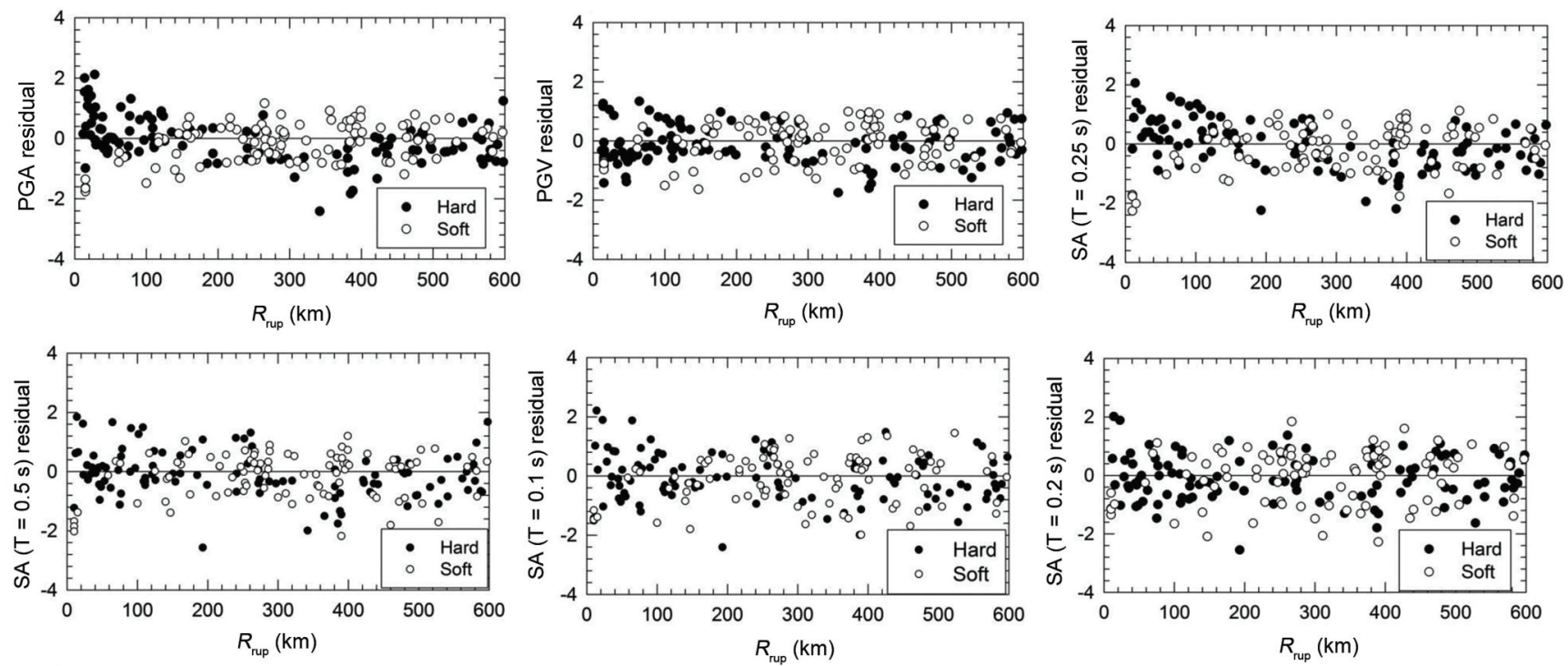

Figure 4. Residuals in natural logarithmic unit as a function of distance for the proposed GMPE.

functional form. Figure 5 compares observed PGA values with the geometric mean PGA curves computed from the proposed GMPE. On average, our model fits the data well, except for the 1986 Kangra $\left(M_{\mathrm{w}}\right.$ 5.5) and 2007 Nepal $\left(M_{\mathrm{w}} 4.3\right)$ earthquakes. Anomalously high PGAs were observed during the Kangra earthquake that are not well reproduced by our model. On the other hand, the model predicts much higher intensities than those observed during the 2007 Nepal earthquake.

\section{Comparison of GMPEs}

In Table 4, we compared our GMPE with those of two other studies. The GMPE of Sharma et al. ${ }^{7}$ was selected because it was constructed partly with data from the
Himalayan arc. We choose GMPE of Zhao et al. ${ }^{29}$ because it has performed well in different seismic regions. The comparison was restricted to the distance range recommended by the authors: $R_{\text {rup }} \leq 100 \mathrm{~km}$, Sharma et al. ${ }^{7}$ and $R_{\text {rup }} \leq 300 \mathrm{~km}$ for Zhao et al. ${ }^{29}$.

Figure 5 shows the observed PGA data and prediction from the three GMPEs. Our GMPE predicts larger amplification of ground-motion intensities at soft sites with respect to hard sites than the other two GMPEs. We note that the GMPE of Sharma et $a l^{7}$, on average, tends to overestimate PGA especially as $M_{\mathrm{w}}$ decreases, while that of Zhao et al. ${ }^{29}$, on average, tends to underestimate PGA, particularly as $M_{\mathrm{w}}$ increases. As expected, the proposed GMPE provides a better fit to the data than the other two models. The trend is similar for other intensities. 

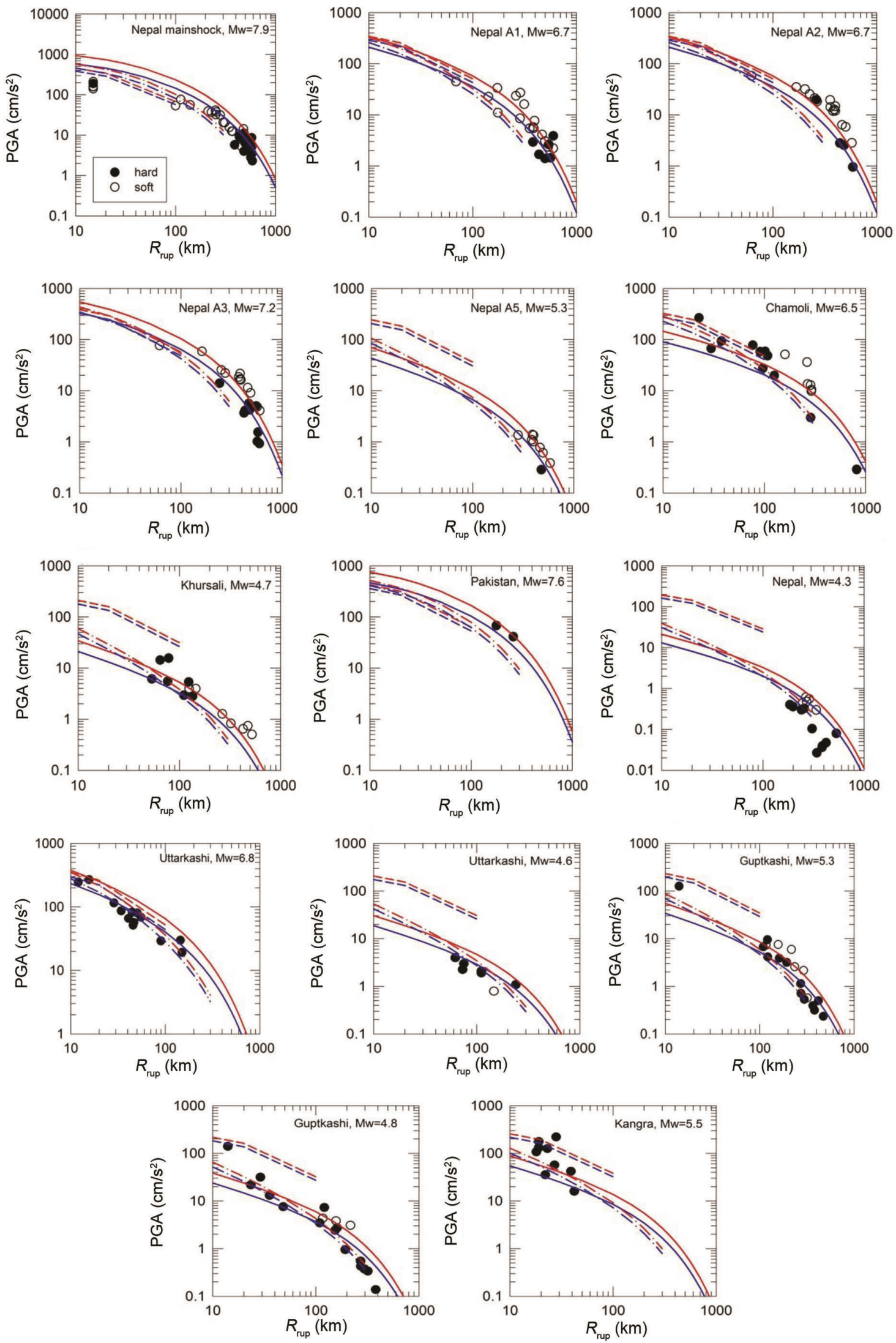

Figure 5. Comparison of observed PGA with expected median curves from different GMPEs. Continuous line: this study; dashed line: Sharma et al. ${ }^{7}$; dot-dashed line: Zhao et al. ${ }^{29}$. GMPE predictions for hard and soft sites are shown by blue and red curves respectively. 

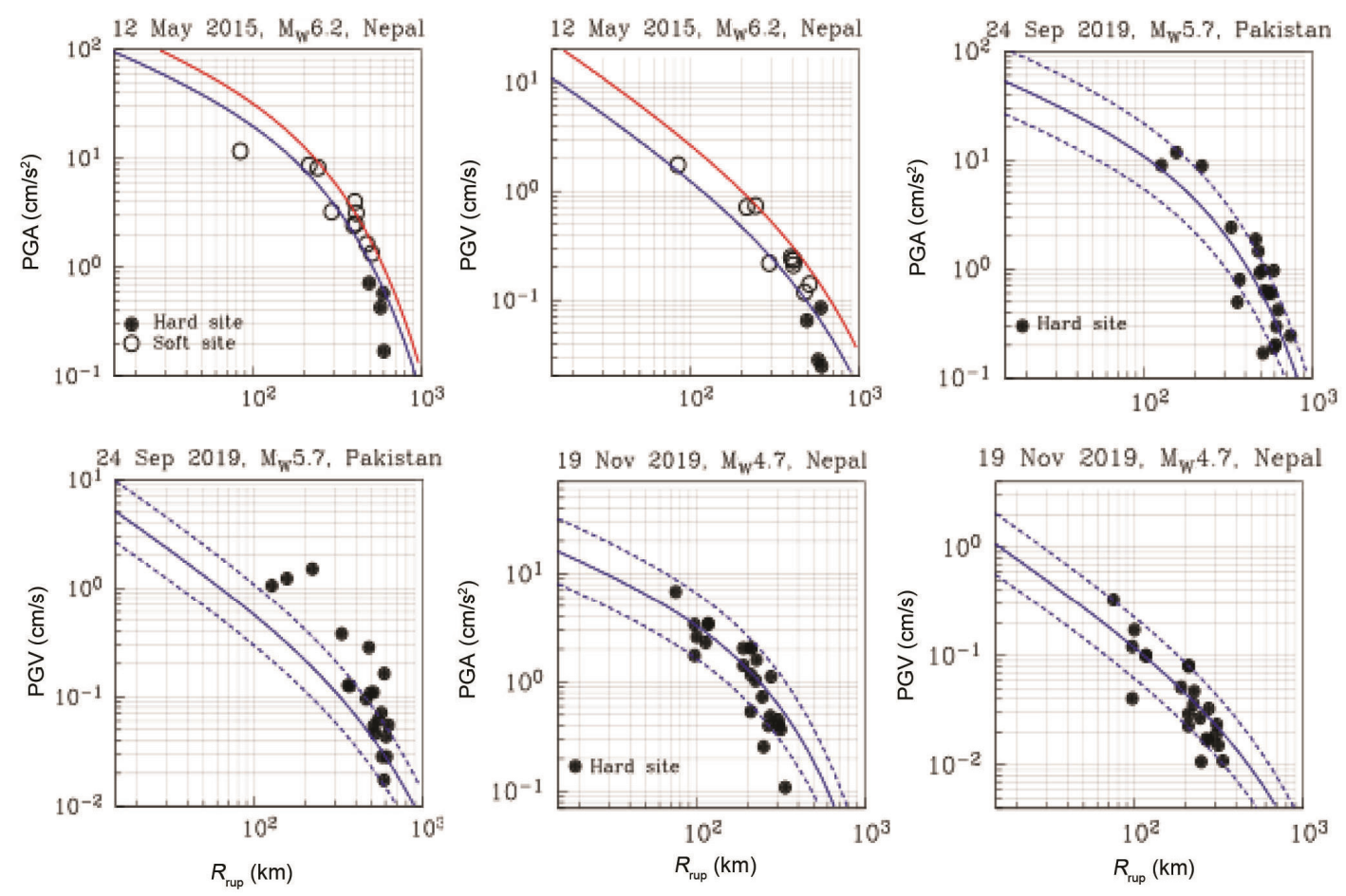

Figure 6. Test of performance of GMPE. Observed and predicted PGA and PGV for aftershock 4 of the Gorkha earthquake (top two frames), Pakistan earthquake of 25 September 2019 (middle two frames), and Nepal earthquake of 19 November 2019 (bottom two frames). GMPE predictions for aftershock 4 at hard and soft sites are shown by blue and red lines respectively, in the top two frames. Three lines in the middle and bottom frames illustrate median and \pm one standard deviation curves.

Table 4. Selected GMPEs for comparison

\begin{tabular}{lccc}
\hline Reference & Region & $\begin{array}{c}\text { Distance } \\
\text { range }(\mathrm{km})\end{array}$ & $\begin{array}{c}\text { Magnitude } \\
\text { range }\end{array}$ \\
\hline $\begin{array}{l}\text { Sharma } \text { et al. } \\
\text { Zhao } \text { et al. }\end{array}$ & $\begin{array}{c}{ }^{7} \\
\text { India, Iran }\end{array}$ & $<100$ & $5-7$ \\
\hline
\end{tabular}

\section{Test of performance of GMPE}

We used data from three earthquakes that were not used in the regression analysis (Table 2) to check the performance of the derived GMPE. Figure 6 shows a comparison of the observed and predicted PGAs and PGVs. In general, the GMPE curves fit PGA and PGV data fairly well, with the exception of the observed PGVs for the 2019 Pakistan earthquake $\left(M_{\mathrm{w}} 5.7\right)$, which are greater than those predicted by the GMPE. This may be due to the source characteristics. It could also be due to path effect, since the seismic waves reaching hard sites in the Himalaya may suffer relatively greater amplification as they partly traverse through the sediments of the IGP (Figure 1).

\section{Conclusion}

It is unfortunate that derivation of a reliable GMPE, valid for earthquakes along the Himalayan arc and crucial for reliable seismic hazard estimation, has been lagging far behind our knowledge of seismo-tectonics and seismic potential at the convergence boundary of the Indian and
Eurasian Plates. In this study, we have taken advantage of the recent increase in the number of earthquakes that have produced recordings at hard sites in the arc and in Peninsular India, and at soft IGP sites to derive a GMPE for earthquakes in the Western Himalayan arc. The dataset consists of 14 earthquakes $\left(4.3 \leq M_{\mathrm{w}} \leq 7.9\right)$ recorded at 104 hard sites and 134 soft sites within a distance of $600 \mathrm{~km}$. Observed PGAs and PGVs of three earthquakes $\left(4.7 \leq M_{\mathrm{w}} \leq 6.2\right)$, not used in the regression analysis, compare well with the predictions of the GMPE.

Our study suffers from limited data, especially of large earthquakes and near-source recordings. The largest event in the dataset is the $2015 M_{\mathrm{w}} 7.9$ Gorkha, Nepal earthquake and there are only two recordings of the $2005 M_{\mathrm{w}}$ 7.6 Pakistan earthquake. A compilation of catalogues of large and great earthquakes in the entire arc by Stevens and Avouac ${ }^{30}$ lists 3-4 events with $M_{\mathrm{w}} \geq 8.5$ per thousand years. Such earthquakes are well outside the range of validity of the GMPE. We recommend caution in using the GMPE for earthquakes above $M_{\mathrm{w}}$ 8.0. Caution is also warranted in using it for eastern Himalayan arc earthquakes, as data from this region were not included in the present analysis.

In recent years, broadband and strong-motion networks in the Western Himalayan arc (in Uttarakhand, Himachal Pradesh and Kashmir) have been strengthened. As a consequence, datasets of $M_{\mathrm{w}} \leq 6.0$ earthquakes may be expected. It may take time before recordings from less frequent, larger earthquakes are obtained. In the 


\section{RESEARCH ARTICLES}

meantime, estimation of ground motion from great earthquakes must rely on data from other regions or hybrid ground motion simulation complementing deterministic approach at low frequencies with stochastic approach at high frequencies.

1. Bilham, R., Larson, K. and Freymueller, J. T., GPS measurements of present-day convergence across the Nepal Himalaya. Nature, 1997, 386, 61-64

2. Jouanne, F. et al., Current shortening across the Himalayas of Nepal. Geophys. J. Int., 2004, 157, 1-14; doi:10.1111/j.1365246X.2004.02180.

3. Larson, K. M., Burgmann, R., Bilham, R. and Freymueller, J. T., Kinematics of the India-Eurasia collision zone from GPS measurements. J. Geophys. Res., 1999, 104, 1077-1093; doi:10.1029/ 1998JB900043.

4. Stevens, V. L. and Avouac, J. P., Interseismic coupling on the main Himalayan thrust. Geophys. Res. Lett., 2015, 42, 5828-5837.

5. Bilham, R., Gaur, V. K. and Molnar, P., Himalayan seismic hazard. Science, 2001, 293, 1442-1444; doi:10.1126/science.1062584.

6. Raghukanth, S. T. G. and Iyengar, R. N., Estimation of seismic spectral acceleration in Peninsular India. J. Earth Syst. Sci., 2007, 116, 199-214

7. Sharma, M. L., Douglas, J., Bungum, H. and Kotadia, J., Groundmotion prediction equations based on data from the Himalayan and Zagros region. J. Earthq. Eng., 2009, 13, 1191-1210; doi:10.1080/13632460902859151.

8. Singh, S. K., Ordaz, M., Dattatrayam, R. S. and Gupta, H. K., A spectral analysis of the 21 May 1997, Jabalpur, India earthquake $\left(M_{\mathrm{w}}=5.8\right)$ and estimation of ground motion from future earthquakes in the Indian shield region. Bull. Seismol. Soc. Am., 1999, 89, 1620-1630.

9. Singh, S. K. et al., Strong ground motion in the Indo-Gangetic Plains during the 2015 Gorkha, Nepal, earthquake sequence and its prediction during future earthquakes. Bull. Seismol. Soc. Am., 2017, 107, 1293-1306; doi:10.1785/0120160222.

10. Sharma, M. L., Attenuation relationship for estimation of peak ground horizontal acceleration using data from strong-motion arrays in India. Bull. Seismol. Soc. Am., 1998, 88, 1063-1069.

11. Singh, S. K., Mohanty, W., Bansal, B. K. and Roonwal, G. S., Ground motion in Delhi from future large/great earthquakes in the central seismic gaps of the Himalayan arc. Bull. Seismol. Soc. Am., 2002, 92, 555-569.

12. Singh, S. K. et al., Estimation of ground motion for Bhuj (26 January 2001; $M_{\mathrm{w}}$ 7.6) and for future earthquakes in India. Bull. Seismol. Soc. Am., 2003, 94, 1564-1570.

13. Singh, S. K. et al., A study of Delhi earthquake of 25 November $2007\left(M_{\mathrm{w}} 4.1\right)$ : implications for seismic hazard. Curr. Sci., 2010, 99, 939-947.

14. Srinagesh, D., Singh, S. K., Suresh, G., Srinivas, D., PérezCampos, X. and Suresh, G., A study of Guptkashi, Uttarakhand earthquake of 6 February $2017\left(M_{\mathrm{w}} 5.2\right)$ in the Himalayan arc and implications for ground-motion estimation. J. Seismol., 2018, 22, 789-803; doi:10.1007/s10950-018-9732-2.

15. Parvez, I. A., Gusev, A. A., Panza, G. F. and Petukhin, A. G., Preliminary determination of the inter dependence among strongmotion amplitude, earthquake magnitude and hypocentral distance for the Himalayan region. Geophys. J. Int., 2001, 144, 577-596; doi:10.1046/j.1365-246x.2001.01335.

16. Boore, D. M., Simulation of ground motion using the stochastic method. Pure Appl. Geophys., 2003, 160, 635-676.

17. Chadha, R. K. et al., CIGN, a strong-motion seismic network in central Indo-Gangetic Plains, foothills of Himalayas: first results. Seismol. Res. Lett., 2016, 87, 37-46; doi:10.1785/0220150106.
18. Kumar, A., Mittal, H., Sachdeva, R. and Kumar, A., Indian strong motion instrumentation network. Seismol. Res. Lett., 2012, 83, 5966; doi:10.1785/gssrl.83.1.59.

19. Kumar, A., Mitra, S. and Suresh, G., Seismo-tectonics of the Eastern Himalayan and Indo-Burman plate boundary systems. Tectonics, 2015, 34, 2279-2295; doi:10.1002/2015TC003979.

20. Sharma, S. and Mitra, S., Seismic attenuation of the Eastern Himalayan and Indo-Burman plate boundary systems, Northeast India. J. Geophys. Res., 2018, 123, 10,797-10,809; https://doi.org/ 10.1029/2018JB016496.

21. Srinagesh, D., Singh, S. K., Chadha, R. K., Paul, A., Suresh, G., Ordaz, M. and Dattatrayam, R. S., Amplification of seismic waves in the central Indo-Gangetic basin, India. Bull. Seismol. Soc. Am., 2011, 101, 2231-2242.

22. Srinivas, D., Srinagesh, D., Chadha, R. K. and Ravi Kumar, M., Sedimentary thickness variations in the Indo-Gangetic Foredeep from inversion of receiver functions. Bull. Seismol. Soc. Am., 2013, 103, 2257-2265; doi:10.1785/0120120046.

23. Takai, N., Shigefuji, M., Rajaure, S., Bijukchhen, S., Ichiyanagi, M., Dhital, M. R. and Sasatani, T., Strong ground motion in the Kathmandu valley during the 2015 Gorkha, Nepal, earthquake. Earth Planets Space, 2016, 68, 1-8; doi:10.1186/s40623-0160383-7.

24. Arroyo, D., García, D., Ordaz, M., Mora, M. A. and Singh, S. K., Strong ground-motion relations for Mexican interplate earthquakes. J. Seismol., 2010, 14, 769-785; doi:10.1007/s10950-0109200-0.

25. Singh, S. K. et al., Analysis of near-source strong motion recordings along the Mexican subduction zone. Bull. Seismol. Soc. Am., 1989, 79, 1697-1717.

26. Ordaz, M., Singh, S. K. and Arciniega, A., Bayesian attenuation regressions and application to Mexico City. Geophys. J. Int., 1994, 117, 335-344.

27. Arroyo, D. and Ordaz, M., Multivariate Bayesian regression analysis applied to ground-motion prediction equations, part 1: theory and synthetic example. Bull. Seismol. Soc. Am., 2010, 100, 1551-1567; doi:10.1785/0120080354.

28. Arroyo, D. and Ordaz, M., Multivariate Bayesian regression analysis applied to ground motion prediction equations, part 2: numerical example with actual data. Bull. Seismol. Soc. Am., 2010, 100, 1568-1577; doi:10.1785/0120090320.

29. Zhao, J. X. et al., Attenuation relations of strong ground motion in Japan using site classification based on predominant period. Bull. Seismol. Soc. Am., 2006, 96, 898-913.

30. Stevens, V. L. and Avouac, J. P., Millenary $M_{\mathrm{w}}>9.0$ earthquakes required by geodetic strain in the Himalaya. Geophys. Res. Lett., 2016, 43, 1118-1123.

ACKNOWLEDGEMENTS. We thank the anonymous reviewer and Imtiyaz Parvez for useful comments. D.S. thanks the Director, CSIRNGRI, Hyderabad for support during the course of the projects undertaken in the Indo-Gangetic Plains and NW Himalaya (ref. no: NGRI/Lib/2020/Pub-21). The GMPE programme is available from D. Srinagesh on request. Data used in this study were contributed by the National Centre for Seismology, New Delhi; CSIR-NGRI, Hyderabad, and Indian Institute of Technology, Roorkee. CIGN instrumentation was acquired under the SATREPS-DISANET Indo-Japanese Collaborative Project. The study was partly supported by the SATREPS programme of JST/JICA; CSIR-NGRI HEART Project. S.K.S. was partially supported by Fondo para la Cooperación Internacional en Ciencia y Tecnología (FONCICYT)-CONACYT 1000/780/2016.

Received 24 February 2020; revised accepted 20 November 2020

doi: $10.18520 / \mathrm{cs} / \mathrm{v} 120 / \mathrm{i} 6 / 1074-1082$ 